\section{El cáncer como inmunodeficiencia secundaria. Revisión}

María Eugenia Vargas-Camaño, ${ }^{1}$ Ricardo Leopoldo Guido-Bayardo, ${ }^{2}$ Nora Ernestina Martínez-Aguilar, ${ }^{3}$ María Isabel Castrejón-Vázquez ${ }^{1}$

\section{Resumen}

Las inmunodeficiencias secundarias aparecen en individuos previamente inmunocompetentes. La falta de respuesta primaria o secundaria a un antígeno extraño, en el caso de infecciones, es un dato centinela en el diagnóstico de inmunodeficiencia (puede ser primaria o secundaria); en el caso de un antígeno propio podría generar cáncer. Éste ha mostrado un aumento en la prevalencia e incidencia en forma global. La mayor parte de los tratamientos médicos actuales en cáncer se enfocan, fundamentalmente, a acciones inmunomoduladoras (inmunosupresióninmunoestimulación o ambos). El conocimiento de los conceptos clave, desde la perspectiva de la inmunidad innata y adquirida, conduce al desarrollo de cáncer, involucrándose a la vigilancia inmunológica y los mecanismos de escape de ésta, que contribuyen a comprender mejor el origen, comportamiento y tratamiento de las neoplasias. Los tratamientos pueden originar alteraciones inmunológicas como: alergia, anafilaxia, falta de respuesta por inmunogenicidad, campos de atención del especialista en Alergia e Inmunología clínica.

PALABRAS CLAVE: cáncer, inmunodeficiencia secundaria, inmunocompetentes, tratamientos inmunomoduladores.

Rev Alerg Méx 2016 Apr-Jun;63(2):169-179.

\section{Cancer as secondary immunodeficiency. Review}

María Eugenia Vargas-Camaño, ${ }^{1}$ Ricardo Leopoldo Guido-Bayardo, ${ }^{2}$ Nora Ernestina Martínez-Aguilar, ${ }^{3}$ María Isabel Castrejón-Vázquez ${ }^{1}$

\begin{abstract}
secondary immunodeficiency's, previously presented in immunocompetent individuals. The lack of primary or secondary response to the presence of a foreign antigen, in the case of infections is a sentinel data in the diagnosis of immunodeficiency (can be primary or secondary), in the case of a self antigen may generate the presence of Cancer. Cancer has shown an increase in the prevalence and incidence globally. Most current medical treatments in cancer are focused primarily on immunomodulatory actions (immunosuppression / immune stimulation or both). Knowledge of key concepts from the perspective of innate and acquired immunity lead to cancer development, engaging immune surveillance and escape mechanisms of this that contribute to better understand the origin, behavior and treatment of neoplasm's. These treatments can cause immunological disorders such as allergy, anaphylaxis,
\end{abstract}

\footnotetext{
${ }^{1}$ Servicio de Inmunología Clínica y Alergia, Centro Médico Nacional 20 de Noviembre, Instituto de Seguridad y Servicios Sociales de los Trabajadores del Estado, Ciudad de México, México.

${ }^{2}$ Servicio Inmunología Clínica y Alergia. Hospital MG, Ciudad de México, México

${ }^{3}$ Servicio de Pediatría, Inmunología Clínica y Alergia, Centro Médico Coyoacán, Ciudad de México, México.
}

Recibido: 11 de marzo 2016

Aceptado: 18 de abril 2016

\section{Correspondencia}

Dra. María Eugenia Vargas-Camaño Teléfono: 52005003, extensión 14523. genavargas@gmail.com

Este artículo debe citarse como Vargas-Camaño ME, Guido-Bayardo RL, MartínezAguilar NE, Castrejón-Vázquez MI. El cáncer como inmunodeficiencia secundaria. Revisión. Rev Alerg Méx. 2016 abr-jun;63(2):169-179. 
lack of response immunogenicity care fields specialist in Allergy and Clinical Immunology.

KEYWORDS: Cancer, Secondary Immunodeficiency, Immunocompetent, Immunomodulatory treatments.
Correspondence

Dra. María Eugenia Vargas-Camaño Teléfono: 52005003, extensión 14523. genavargas@gmail.com

\section{ANTECEDENTES}

Las inmunodeficiencias secundarias aparecen en individuos sin alteraciones genéticas en el sistema inmunitario inmunocompetente. La función esencial del sistema inmunitario es el reconocimiento entre lo propio y lo no propio; por ejemplo, la erradicación de las infecciones. La respuesta inmunitaria es el mecanismo por el que un organismo intenta mantener la integridad del genoma. Las células inmunitarias pueden identificar antígenos no propios expresados en la superficie de una célula infectada (proteínas virales o bacterianas) y hacer de ésta su blanco y destruirla. La falta de respuesta inmunitaria primaria o secundaria ante un antígeno propio es un dato que debe despertar sospecha en el diagnóstico de inmunodeficiencia (primaria o secundaria), y que en el caso de un antígeno propio podría generar cáncer.

La renovación celular continúa durante la vida de todos los individuos, y durante este proceso se generan algunas mutaciones en las células, éstas son eliminadas y reconocidas por un sistema inmunitario íntegro. De no ser así se podría originar cáncer, por estos mecanismos, reconociéndolo actualmente como una inmunodeficiencia secundaria. Por primera vez Paul Erlich, a mediados del siglo XIX, propuso que los tumores podrían ser reconocidos como tejidos cancerígenos y antigénicamente extraños para el huésped, y consideró a la activación de la respuesta inmunitaria como un mecanismo importante que podría contribuir al tratamiento del cáncer. En 1970 Burnet y sus colaboradores propusieron el concepto de sobrevigilancia inmunológica y se inició la descripción de pacientes con deficiencia de respuesta clínica ante la existencia de células cancerosas con base en tres observaciones:

1. Existencia de regresiones espontáneas de cáncer.

2. Aumento de la incidencia de cáncer en pacientes inmunosuprimidos.

3. Existencia de infiltrados linfocitarios en tumores sólidos.

Entre las funciones importantes del sistema inmunitario está proporcionar protección contra la proliferación excesiva de las células neoplásicas, y quizá en la mayor parte de los cánceres esta actividad no sea exitosa.

La respuesta inmunitaria tumoral se dirige al reconocimiento de:

1. Las propiedades antigénicas de las células tumorales.

2. Reconocer a la respuesta inmunitaria del hospedero contra las células tumorales.

3. Las consecuencias inmunológicas del hospedero relacionadas con el crecimiento de células tumorales.

4. Valiéndose de los medios por los que puede modularse el sistema inmunitario pueden identificarse las células tumorales, para promover la erradicación del tumor. 
Por ello, uno de los retos es diferenciar las células tumorales de las normales porque existen muchas similitudes entre ambas, excepto que las primeras tienden a proliferar en forma anormal, explicando con esto la capacidad de diseminarse por todo el hospedero, sin funciones diferenciadas específicas o ciclos apoptósicos regulados, por lo que no realizan una función diferenciada específica que interfiera con la función de los órganos. Las células normales tienen un índice de pérdida celular por apoptosis programada que se correlaciona con la producción de nuevas células que se encuentran como reservas celulares menos maduras, mecanismos estudiados y demostrados por diferentes autores.

La prevalencia e incidencia del cáncer se han incrementado en forma global. La mayor parte de los tratamientos médicos actuales en cáncer está enfocada, fundamentalmente, a las acciones inmunomoduladoras (inmunosupresión-inmunoestimulación, o en combinaciones diversas). Estos tratamientos pueden originar alteraciones inmunológicas como: alergia, anafilaxia, falta de respuesta por inmunogenicidad, que son campos de atención del especialista en Inmunología Clínica y Alergia.

El conocimiento de conceptos clave contribuirá a comprender mejor el origen, comportamiento y tratamiento de las neoplasias, como: vigilancia inmunológica y los mecanismos de evasión por parte de la inmunidad innata y adquirida. Algunos ejemplos son los anticuerpos monoclonales y la respuesta inmunitaria celular, inducida por citocinas $u$ otros mediadores. Finalmente, las barreras de superficie (piel, moco, $\mathrm{pH}$, microbiota) indudablemente participan en la formación del tumor.

\section{Cáncer}

Como generalidad, en la aprición de cualquier tipo de cáncer o neoplasia maligna, las células resistentes a la eliminación tienen como rasgos distintivos:

1. La capacidad de sostener la señalización y la inmortalidad proliferativas.

2. Resistir la muerte celular.

3. Inducir angiogénesis.

4. Activar la invasión y metástasis.

5. Evadir a los supresores del crecimiento. ${ }^{1}$

En estas condiciones, el sistema inmunitario no tiene la capacidad para reconocer o eliminar este tipo de células que darán origen a un cáncer, no sólo en situación de falta de vigilancia inmunológica, sino también cuando existan respuestas inmunitarias no resueltas, como la inflamación crónica. En otras palabras, el sistema inmunitario de un individuo es capaz de atenuar el crecimiento tumoral sin causar toxicidad a los tejidos normales, conservando una respuesta de memoria antitumoral o, por el contrario, promover la proliferación maligna. ${ }^{2}$ El cáncer y los tratamientos contra el cáncer debilitan al sistema inmunitario.

\section{Vigilancia inmunitaria}

Las primeras y escasas células con transformación maligna son detectadas por las células asesinas naturales (NK) a través de sus ligandos específicos en dichas células, Ilevando a su destrucción. Los macrófagos y células dendríticas recogen y procesan los fragmentos de estas células destruidas para activar la secreción de citocinas inflamatorias y presentar estas moléculas derivadas del tumor a las células T y B. Esto promueve la mayor producción de citocinas adicionales que activan aún más a la inmunidad innata y la producción de anticuerpos y células T (TC) específicas para tumor. La capacidad completa del sistema inmunitario adquirido con sus efectores específicos (anticuerpos, TCD4+, TCD8+) elimina a las células cancerosas rema- 
nentes. Este proceso, denominado vigilancia inmunitaria, tiene actualmente al menos tres desenlaces reconocidos: eliminación, equilibrio y escape. ${ }^{3}$

Eliminación: un tumor sumamente inmunogénico en un individuo inmunocompetente conduce a una óptima estimulación del sistema inmunitario innato, con una elevada producción de citosinas inmunoestimulantes, inflamación aguda, y activación de gran número de linfocitos $\mathrm{T}$ y $\mathrm{B}$, eliminando al tumor que emerge.

Equilibrio: en la situación de un individuo menos inmunocompetente o un tumor menos inmunogénico, algunas células malignas escapan a la vigilancia y a largo plazo, entre episodios de activación del sistema inmunitario y eliminación de las células tumorales, el tumor tendrá un lento crecimiento.

Escape: cuando las interacciones tumor-sistema inmunitario estimulan el crecimiento de un cáncer. Existe un aumento de células inmunosupresoras, como los linfocitos T reguladores (Treg) asociados con citosinas también inmunosupresoras como el TGF- $\beta$ (factor transformante de crecimiento de fibroblastos beta), que participan en la metástasis, ${ }^{4}$ producción de interleucina-10 (IL-10), células supresoras de derivación mieloide (MDSC) y células $\mathrm{TCr}$ poco efectoras. ${ }^{4} \mathrm{El}$ tumor, por sí mismo, también puede producir sustancias inmunosupresoras, como la prostaglandina E2 (PGE-2). ${ }^{5}$

\section{Antígenos asociados a tumor (AAT)}

El cáncer representa una carga antigénica muy extensa que se identifica cuando se detecta el crecimiento del tumor por los métodos diagnósticos habituales. Los marcadores tumorales hasta ahora desarrollados carecen de la precisión necesaria para determinar la existencia subclínica de una neoplasia maligna, además de que pueden identificarse en otras afecciones en donde no hay cáncer.

La capacidad de destrucción tumoral por el sistema inmunitario reside en el reconocimiento de antígenos asociados a tumor. La evasión inmunitaria de la neoplasia está condicionada por la falta de reconocimiento de estos antígenos. Durante las últimas cuatro décadas se han tipificado antígenos asociados a tumor, con diversos objetivos:

- Para investigar la respuesta inmunitaria capaz de iniciar o evadir.

- Para ayudar a mejorar la detección temprana del tumor, utilizándolos como marcadores.

- Para evaluar la respuesta a los tratamientos.

- Como criterios en el diagnóstico y pronóstico.

- Como blancos terapéuticos (de anticuerpos monoclonales).

- Para producción de vacunas antitumorales.

En el Cuadro 1 se muestra la clasificación de los antígenos asociados al tumor ${ }^{6}$ y su relación con el complejo mayor de histocompatibilidad (MHC).

\section{Antígenos del complejo mayor de histocompatibilidad (MCH)}

Además de la pérdida de antígenos asociados al tumor, que modifican su inmunogenicidad, las células tumorales pueden perder moléculas de los antígenos leucocitarios humanos o del complejo mayor de histocompatibilidad. La inducción de una respuesta inmunitaria por células $T$ requiere de la presentación de los antígenos por células presentadoras de antígeno. Las células presentadoras de antígeno pueden ser monocitos, macrófagos, linfocitos B y células dendríticas. Éstas pueden capturar antígenos tumorales y presentarlos a las células $\mathrm{T}$ asociadas a moléculas del complejo mayor 
Cuadro 1. Clasificación de antígenos asociados con tumores

\begin{tabular}{|c|c|c|}
\hline Antígeno & Denominación & Expresión en cáncer \\
\hline $\begin{array}{l}\text { Cáncer de testículo } \\
\text { (CT) } \\
\text { Silentes en testículo } \\
\text { normal }\end{array}$ & $\begin{array}{l}\text { MAGE } \\
\text { SSX2 (HOM-MEL-40) } \\
\text { NY-ESO }\end{array}$ & $\begin{array}{l}\text { Melanomas, carcinomas de testículo, pulmón y vejiga }{ }^{26} \\
\text { Melanomas, cáncer de colon, cáncer de mama, hepatocarcinomas, } \\
\text { condrosarcomas } \\
\text { Cáncer de testículo, melanomas, condrosarcomas }{ }^{28}{\text { liposarcomas }{ }^{29}}^{29}\end{array}$ \\
\hline $\begin{array}{l}\text { Codificados por genes } \\
\text { mutados }\end{array}$ & $\begin{array}{l}\text { p53 } \\
\text { CDK4 (cyclin dependent kinase 4) }\end{array}$ & $\begin{array}{l}\text { Células normales, cáncer de mama, colon, cervical, próstata, } \\
\text { colorrectal, pulmón } \\
\text { Cáncer de mama }{ }^{30} \text { y páncreas, }{ }^{31} \text { melanoma }{ }^{32}\end{array}$ \\
\hline De diferenciación & Tirosinasa Melan-A/MART 1 & $\begin{array}{l}\text { Piel, sobre todo melanoma. Autoinmunidad: vitíligo, }{ }^{33} \text { cáncer } \\
\text { de mama }{ }^{34} \\
\text { melanoma, }^{35} \text { sarcoma de células claras }{ }^{36}\end{array}$ \\
\hline $\begin{array}{l}\text { Productos genéticos } \\
\text { amplificados }\end{array}$ & $\begin{array}{l}\text { HER2/neu } \\
\text { Anhidrasa carbónica }\end{array}$ & $\begin{array}{l}\text { Cáncer pulmonar, }{ }^{37} \text { gástrico, de mama y ovario, } 38 \\
\text { II: leucemias de varias estirpes, }{ }^{39} \text { IX: carcinoma renal }{ }^{40} \text {, cervi- } \\
\text { cal }^{41} . \text { XII: carcinoma renal }{ }^{42}\end{array}$ \\
\hline Virales & $\begin{array}{l}\text { Retrovirus } \\
\text { Virus del papiloma humano (HPV) } \\
\text { Virus de Epstein-Barr (EBV) }\end{array}$ & $\begin{array}{l}\text { Próstata. Cánceres experimentales } \\
\text { Cáncer cervicouterino, }{ }^{44} \text { de pene }{ }^{45} \text { yorofaríngeo }{ }^{46} \\
\text { carcinoma nasofaríngeo, }{ }^{47} \text { linfomas }^{48} \text {. }\end{array}$ \\
\hline
\end{tabular}

Nota: antígenos del complejo mayor de histocompatibilidad (MHC)

de histocompatibilidad clase I o II, expresando moléculas coestimuladoras. Una respuesta adecuada de células $\mathrm{T}$ forma parte de la vigilancia inmunológica correcta.

La mayor parte de los péptidos asociados al complejo mayor de histocompatibilidad clase I se cortan y procesan en los proteosomas, se transportan al retículo endoplásmico por proteínas Ilamadas TAP (transportadores asociados al procesamiento antigénico) y se asocian con el complejo mayor de histocompatibilidad para ser presentadas en la superficie de la célula presentadora de antígeno al linfocito. Cualquier defecto en este procesamiento, atribuido a mutaciones en la proteína beta 2 microglobulina o en transportadores asociados al procesamiento antigénico, incide en la capacidad del linfocito para reconocer a la célula tumoral y eliminarla. Estos defectos se han descrito principalmente en los melanomas. ${ }^{7}$

\section{Neutrófilos y macrófagos}

El microambiente tumoral es una compleja red en la que las células mieloides juegan un papel importante en la formación de un tumor desde su inicio, como las metástasis, mostrando su integración a las respuestas inmunitarias innatas y adquiridas participantes. La plasticidad es un rasgo aceptado de las células mieloides, en particular el linaje monocito-macrófago. Incluye la capacidad de desplegar un amplio espectro de estados de activación en respuesta a las distintas señales, y los macrófagos clásicos M1 o los macrófagos alternos M2, ${ }^{8}$ representan el paradigma de este rasgo. En el infiltrado inflamatorio de varios tumores existen macrófagos asociados al tumor (TAM) que producen numerosos mediadores (como las quimiocinas) responsables de sostener el proceso inflamatorio crónico.

Los neutrófilos polimorfonucleares son las células inmunitarias circulantes más abundantes; se consideran las principales células efectoras terminalmente diferenciadas, primera línea de defensa contra la infección, resistencia a los microbios y primordiales durante la fase aguda de la inflamación. Esto es un punto de vista limitado que se ha cuestionado según la evidencia reciente. El microambiente que rodea a un tumor sólido 
típicamente posee muchas de las características de la inflamación crónica, situación que le es favorable para su crecimiento y diseminación. En circunstancias donde exista un cambio en el estado inflamatorio crónico agudo, los polimorfonucleares pueden convertirse en células anticancerosas efectoras muy eficientes. En varios reportes clínicos esto se ha asociado con un efecto antitumoral inesperado. El factor estimulante de colonias de granulocitos induce neutrofilia intensa y sostenida, lo que sugiere que un infiltrado peritumoral de este tipo puede representar una forma efectiva de luchar contra el cáncer. ${ }^{9,10}$ Hay neutrófilos asociados con el tumor que pueden polarizarse en diferentes fenotipos en respuesta a estímulos derivados del tumor. Los neutrófilos asociados con el tumor pueden ejercer funciones tumorales y antitumorales, lo que explica que en el crecimiento tumoral se condiciona la expansión de otra población de células mieloides (MDSC) que tienen función inmunosupresora, en donde es bien conocido que las citosinas (IL-6, TNF, IL-1 $\beta$ e IL-23) que derivan de estas células mieloides, son reconocidas generalmente como fuerzas promotoras de tumores dominantes, que se han clasificado y encontrado en ratones. Todas estas poblaciones tienen mecanismos epigenéticos diversos para su expresión. ${ }^{11}$

\section{Linfocitos B, T y NK}

En un experimento se demostró que el sistema inmunitario puede prevenir la aparición de tumores al proporcionar una fuerte protección contra el cáncer. ${ }^{12}$

Cada uno de los linfocitos B diferenciado en célula plasmática está programado para producir un anticuerpo específico contra un antígeno específico que le fue presentado por una célula presentadora de antígeno que libera citocinas, como IL1 y TNF, con la cooperación del linfocito T cooperador CD4+ Th, a través del complejo mayor de histocompatibilidad clase II.
Los linfocitos Th CD4+ liberan una citocina característica (IL-2) que tiene entre sus funciones la proliferación de linfocitos después de la activación por un antígeno específico.

Las células cancerosas pueden inducir la producción de anticuerpos que pueden adherirse a su superficie y facilitar la destrucción por las células "asesinas" NK a través de esta interacción o por fijación de complemento. Además, las células NK son capaces de eliminar, por sí mismas, a las células tumorales. Hay una deficiencia en función de NK detectadas en cáncer de pulmón, aunque su número total está aumentado. ${ }^{13}$ Las células T citotóxicas CD8+ (Tcit), las células Th1 $\mathrm{CD} 4+$, productoras de interferón gamma (IFN- $\gamma)$ funcionan como las mayores células efectoras antitumorales.

Algunos AAT son reconocidos por células presentadoras de antígeno, sobre todo por CD y presentados a los linfocitos Th CD4+ a través de moléculas MHC clase II, con activación de células efectoras Tcit, por medio de la producción de IL-2 e INF- $\gamma$, las Tcit reconocen AAT a través del complejo mayor de histocompatibilidad clase I para aumentar la destrucción de las células neoplásicas. En un escenario de eliminación tumoral, como previamente se comentó, el individuo inmunocompetente en quien aparece un tumor sumamente inmunogénico se producirán células $\mathrm{T}$ reguladoras CD4+ CD25+ Foxp3+ (Treg) que dirigirán e iniciarán la cancelación de la respuesta inmunitaria cuando las células cancerosas hayan sido eliminadas.

En otro escenario el tumor puede evadir esta respuesta inmunitaria. Las Treg, con sus citocinas inmunorreguladoras, como TGF- $\beta$ y Th17, pueden funcionar como inmunosupresoras o inflamatorias, ayudar al crecimiento y diseminación del cáncer. Cada neoplasia parece expresar uno o varios mecanismos de evasión, todos ellos diferentes. 


\section{Otros factores asociados con el cáncer}

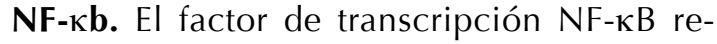
gula importantes procesos celulares desde el establecimiento de respuestas inmunitarias e inflamatorias a la regulación de la proliferación celular o apoptosis, a través de la inducción de gran regulación y alineación de genes blanco, mecanismo reconocido de manera importante en la tumorogénesis porque ejerce fuertes funciones antiapoptóticas en las células cancerosas.

El factor de transcripción NF-KB se activa con tratamientos, como las quimio y radioterapias, para eliminar a las células cancerosas mediante la inducción de apoptosis. La inhibición del factor de transcripción NF-кB aumenta la sensibilidad de las células cancerosas a la acción apoptósica de diversos efectores, como el TNF $\alpha$, quimio o radioterapia. ${ }^{14}$

VEGF. El factor de crecimiento vascular endotelial (VEGF) es una glicoproteína homodimérica y un factor clave en la angiogénesis que se une a sus receptores específicos en células vasculares endoteliales VEGF-1 y VEGF-2. VEGF que promueven a la angiogénesis en cáncer. La nueva vasculatura tumoral que desarrolla es desorganizada, frágil, condiciona hemorragia e hipoxia que, a su vez, aumenta aún más la producción deVEGF. ${ }^{15}$ Experimentalmente se ha demostrado que el factor de crecimiento vascular endotelial también inhibe la maduración funcional de las células dendríticas, disminuye los cocientes LT/ LB en órganos linfoides periféricos e induce atrofia tímica, situaciones que favorecen el crecimiento de tumores. ${ }^{16}$

TLR. Los receptores tipo Toll (TLRs) pertenecen al grupo de receptores de reconocimiento de patógenos de la superficie celular del sistema inmunitario innato. Algunos elementos del medio ambiente o el tabaquismo tienen efectos inmunitarios importantes en las diversas vías de la respuesta innata mediadas por los receptores tipo Toll. Se ha encontrado una estrecha asociación entre polimorfismos de los genes de receptores tipo Toll y la susceptibilidad hacia diversos tumores malignos. En el cáncer, la expresión de receptores tipo Toll aún está en debate, debido a los resultados contradictorios que indican que tanto la inducción de la apoptosis, como la progresión del tumor, podrían depender de la señalización de receptores tipo Toll; algunos datos recientes más bien muestran un efecto pro-tumorigénico. Algunos cánceres relacionados con la modulación de receptores tipo Toll se asocian con algunas infecciones en particular, en las que se incrementa la expresión de receptores tipo Toll, lo que favorece el proceso carcinogénico a través de la inducción de la inflamación; por ejemplo, la asociación del polimorfismo de TLR2 $\Delta 22$, tabaquismo y cáncer gástrico. Así mismo, tantoTLR5 como TLR7 se expresan en grandes cantidades en el carcinoma adenoide quístico de glándulas salivales, tanto en las membranas celulares, como en el citoplasma viral.

\section{Leucemias y linfomas}

La diseminación del cáncer en la médula ósea detiene la producción de todas las progenies celulares hematológicas coexistentes y son fundamentales en la respuesta inmunitaria contra la infección y el cáncer. Esto sucede más frecuentemente en las leucemias o linfomas, pero puede ocurrir con invasión de la médula ósea por otros tipos de cáncer. La médula ósea afectada se altera aún más por otros factores relacionados, principalmente terapéuticos, como la quimioterapia, las terapias biológicas y la radioterapia, que producen alteraciones celulares temporales en el sistema inmunitario innato y adaptativo, lo que a su vez hace que aumente el riesgo de infecciones, principalmente virales. Esos mismos cambios pueden observarse cuando se administran dosis muy altas de corticoides. Los 
pacientes con mieloma múltiple en fase plana tienen mayor riesgo de infecciones bacterianas que amenazan la vida y una inmunosupresión humoral policlonal.

La terapia celular es una alternativa prometedora para la quimioterapia y radioterapia en el cáncer. Las células NK, en particular, tienen un gran potencial para su uso en la inmunoterapia como terapia alternativa en cáncer y para mejorar el efecto de injerto contra huésped del trasplante de células madre hematopoyéticas, en la terapia de las leucemias.

\section{Cáncer de ovario}

Las pacientes con cáncer de ovario tienen una respuesta inmunitaria celular normal, pero menor cantidad de células positivas con inmunoglobulinas de superficie y disminución de la producción de anticuerpos, con función anormal de linfocitos B. ${ }^{17}$ Además, se ha documentado un aumento de Treg que influye en el crecimiento del tumor. ${ }^{18}$

\section{Gliomas y neuroblastoma}

El neuroblastoma es un tumor extracraneano sólido, de aparición en la infancia, con mal pronóstico de supervivencia en fases avanzadas. Está demostrado que las células de neuroblastoma, humanas y murinas, ejercen actividades inmunosupresoras locales y sistémicas, por aumento de la actividad de arginasa. La isoforma predominante que expresan es arginasa II, que inhibe la activación de células mieloides y la inhibición de la proliferación del progenitor CD34+ en médula ósea, además de suprimir la proliferación específica de células $T$ y su acción de citotoxicidad. Los pacientes con concentraciones de expresión más elevadas de arginasa II tienen peor pronóstico de supervivencia quizá asociada con la eficacia subóptima de los tratamientos. ${ }^{19}$
Los gliomas son resistentes a los tratamientos debido a: ${ }^{20}$

- La barrera hematoencefálica que funciona para excluir elementos del sistema inmunitario del tumor y del parénquima cerebral.

- En el sistema nervioso central no hay tejidos linfáticos secundarios organizados para apoyar respuestas inmunitarias locales eficientes.

- En el sistema nervioso central existen bajos niveles de expresión de las proteínas del complejo mayor de histocompatibilidad.

- Hay una aparente escasez de células presentadoras de antígeno más eficientes (células dendríticas).

- Se producen factores inmunosupresores derivados del glioma, como TGF- $\beta$ que interfiere en respuestas inmunitarias locales.

\section{Cáncer colorrectal}

Las lesiones tumorales con mayor infiltración linfocitaria, sobre todo del tipo CD8+, tienen mejor pronóstico; por eso algunos autores proponen una clasificación diferente de la TNM con base en este tipo de infiltrados. ${ }^{21}$ En algunos pacientes con cáncer colorrectal a quienes se extirpó por completo el tumor o en donde se observó aumento de las metástasis, a pesar del tratamiento, se encontró aumento de los complejos inmunitarios circulantes y en las concentraciones de IgA, lo que puede asociarse con disminución del antígeno carcinoembrionario, que es un marcador oncogénico, y que podría interpretarse en forma inadecuada para el diagnóstico de cáncer. ${ }^{22}$

Es imposible abordar, aunque sea de forma resumida, el estado actual de la inmunoterapia contra el cáncer. Existen casi 200 medicamentos biotecnológicos registrados para esta intención terapéutica. 
Sólo se hará mención de algunas medidas generales importantes para sostener un mejor equilibrio inmunitario en el tratamiento de un paciente con cáncer:

- En el paciente con cáncer deben evitarse la desnutrición o la obesidad. La desnutrición asociada con cáncer es multifactorial: sustancias producidas por el tumor y en respuesta al mismo, tratamientos, ansiedad y depresión: las citocinas inflamatorias y hormonas se asocian con desnutrición y caquexia. ${ }^{23}$ La desnutrición debe revertirse con suplementos nutricionales como el ácido graso poliinsaturado icosapentaenoico. ${ }^{24}$

- Si el paciente cursa con comorbilidad metabólica, debe haber una vigilancia estricta de ésta.

- Vigilar estrechamente la salud bucal del enfermo con cáncer, porque los tratamientos pueden empeorar las caries y la enfermedad periodontal. Recientemente se demostró que gérmenes como Fusobacterium nucleatum, un gramnegativo anaeróbico común en la boca, primariamente una bacteria periodontal, pueden inhibir la actividad de las células NK que protegen que se inicie la formación de una neoplasia. ${ }^{25}$

De acuerdo con la clasificación de los antígenos asociados con tumores se observa un vínculo muy estrecho e importante entre el antígeno reconocido, la denominación o nomenclatura y la expresión del cáncer en los diferentes órganos y sistemas. ${ }^{27-49}$

A nivel mundial, una quinta parte de los cánceres en la población se relacionan con infecciones virales. Entre ellos, gamma herpes virus, específicamente HHV4 (EBV) y HHV8 (VHSK), ambos agentes virales oncogénicos se han asociado con gran número de tumores malignos. Los virus recurren a diferentes mecanismos para inducir cáncer, a través de la utilización del ci- clo celular, apoptosis, modulación inmunitaria, modificación epigenética, y la alteración de las vías de transducción de señales. Es importante establecer diferencias puntuales entre cambios infecciosos en donde se considera a las células del sistema inmunitario capaces de identificar antígenos extraños expresados en la superficie de una célula infectada, como proteínas virales o bacterianas y hacer blanco en estas células para su destrucción. La falta de respuesta a las infecciones debe considerarse un dato relevante en el diagnóstico de inmunodeficiencia, que puede ser primaria o secundaria y, como sucede en el cáncer, esta falta de respuesta inmunológica ante un antígeno propio puede generar cáncer. ${ }^{50-54}$

\section{REFERENCIAS}

1. Hanahan D, Weinberg RA. Hallmarks of cancer: the next generation. Cell. 2011;144:646-674.

2. Whiteside TH, Robinson BWS, June GH, Lotze MT. Principles of tumour immunology. In: Robert E Rich Ed. Clinical Immunology. 4a ed. 2013;925-934

3. Schreiber RD, Old LJ, Smyth MJ. Cancer immunoediting: integrating immunity's roles in cancer suppression and promotion. Science 2011;331:1565-1570.

4. Finn OJ. Immuno-oncology: understanding the function and dysfunction of the immune system in cancer. Ann Oncol 2012; 23 (Sup. 8): viii6-viii9, doi:10.1093/annonc/mds256.

5. Mnich SJ, Veenhuizen AW, Monahan JB, Sheehan KC, Lynch $K R$, et al. Characterization of a monoclonal antibody that neutralizes the activity of prostaglandin E2. J Immunol 1995;155: 4437-4444

6. Stockert E, Jäger E, Chem Y-T, Scanlan MJ, Gout I, Karbach J, et al. A Survey of the Humoral Immune Response of Cancer Patients to a Panel of Human Tumor Antigens. J Exp Med 1998; 187 (8): 1349-1354.

7. Salazar FO. El sistema inmunológico, herramienta estratégica en la batalla contra el cáncer. Rev Chil Ped 2000; 71; 4 http://dx.doi.org/10.4067/S0370-41062000000400003

8. Vargas-Camaño ME. Inmunodeficiencias secundarias de tipo metabólico. 1a. Parte. Galenus; 2015;2(6): 6-10.

9. Galdieroa MR, Bonavitas E, Barajonc I, Garlandaa C, Mantovania A, Jaillona S. Tumor associated macrophages and neutrophils in cancer. Inmunobiol 2013; 218(11:1402-1410 doi:10.1016/j.imbio.2013.06.00

10. Soulo JC, Via L, Brú A. Polymorphonuclear neutrophils and cancer: Intense and sustained neutrophilia as a treatment against solid tumors. Med Res Rev 2011; 31 (3): 311-363. DOI:10.1002/med.20185 
11. Mantovani A. Macrophages, Neutrophils, and Cancer: A Double Edged Sword. New Journal of Science Vol. 2014, Article ID 271940, 14 pages http://dx.doi. org/10.1155/2014/271940

12. Shankaran V, Ikeda H, Bruce AT, White JM, Swanson PE, Old $\mathrm{LJ}$, et al. IFN- $\gamma$ and lymphocytes prevent primary tumour development and shape tumour immunogenicity. Nature 2001; 410, 1107-1111 doi:10.1038/35074122

13. Al Omar SY. Marshall E, Middleton D, Christmas SE. Increased numbers but functional defects of $\mathrm{CD} 56+\mathrm{CD} 3+$ cells in lung cancer. International Immunology, Vol. 24(7): 409-415 doi:10.1093/intimm/dxr122

14. Magné $N$, Toillon RA, Bottero $V$, Didelot $C$, Van Houtte $P$, Gérard JP, Peyron JF. NF-KB modulation and ionizing radiation: mechanisms and future directions for cancer treatment. Cancer Let 2006;231:158-168.

15. Camellet P. VEGF as a key mediator of angiogenesis in cancer. Oncology 2005; 69 (Sup 3): 4-10.

16. Carbone DP. Immune Dysfunction in Cancer Patients Cancer Network. January 2002: 1-10.

17. Mandell GL, Fisher RI, Bostick F, Young RC. Ovarian cancer: A solid tumor with evidence of normal cellular immune function but abnormal B cell function. Am J Med 1979; 66; 621-62.

18. Curiel TJ, Coukos G, Zou L, Alvarez X, Cheng P. Mottram P, et al. Specific recruitment of regulatory $T$ cells in ovarian carcinoma fosters immune privilege and predicts reduced survival. Nature Medicine 2004;10, 942-949. doi:10.1038/ nm1093

19. Mussai F, Egan S, Hunter S, Webber H, Fisher J, Wheat $\mathrm{R}$, McConville $\mathrm{C}$, et al. Neuroblastoma arginase activity creates an immunosuppressive microenvironment that impairs autologous and engineered immunity. Can Res Published Online First June 8, 2015; DOI: 10.1158/00085472.CAN-14-3443

20. Pollack IF, Okada H, Chambers WH. Exploitation of immune mechanisms in the treatment of central nervous system cancer. SemPediatric Neurol 2000; 7: 131-143

21. Tougeron D, Fauquembergue E, Latouche JB. Inmune response and colorrectal cáncer. (Artículo en francés) Bull Cáncer. 2013 Mar; 100(3):283-94. doi: 10.1684/bdc.2013.1716.

22. Steele G, Lahey S, Rodrick M, Ross D, Deasy J, Zamcheck N, Osteen R, Wilson R. Circulating immune complexes in patients with colorectal cancer. Am J Surg 1983; 145: 549-553.

23. Van Cutsem E, Aren J The causes and consequences of cancer-associated malnutrition. Eur J Oncol Nurs 2005: (9): 51-S63

24. Argilés JM. Cancer-associated malnutrition. Eur J Oncol Nurs 2005;9(S2): S39-S50.

25. Gur C. Ibrahim Y, Isaacson B, Yamin R, AbedJ,GamlieIM. Enk $\mathrm{J}$, et al. Binding of the Fap2 Protein of Fusobacterium nucleatum to Human Inhibitory Receptor TIGIT Protects Tumors from Immune Cell Attack. Immunity. 2015; 42 (2): 344-355.
26. Jungbluth AA, Busam KJ, Kolb D, Iversen K, Coplan K, et al. Expression of MAGE-antigens in normal tissues and cancer. Int J Cancer. 2000 15; 85(4):460-5.

27. Türeci O, Sahin U, Schobert I, Koslowski M, Schmitt H, Schild $\mathrm{H}-\mathrm{J}$, et al. The SSX-2 gene, which is involved in the $\mathrm{t}(\mathrm{X} ; 18)$ translocation of synovial sarcomas, codes for the human tumor antigen HOM-MEL-40. Can Res.1996; 56:4766-4772.

28. Robbins PF, Morgan RA, Feldman SA, Yang JC, Sherry RM, Dudley ME, et al. Tumor Regression in Patients With Metastatic Synovial Cell Sarcoma and Melanoma Using Genetically Engineered Lymphocytes Reactive With NYESO-1. Clin Oncol 2011 Mar 1; 29(7): 917-924, doi:10.1200/ JCO.2010.32.2537.

29. Pollack SM, Jungbluth AA, Hoch BL, Farrar EA, Bleakley M, et al. NY-ESO-1 is a ubiquitous immunotherapeutic target antigen for patients with myxoid/round cell liposarcoma. Cancer. 2012 Sep 15; 118(18):4564-70. doi: 10.1002/ cncr.27446.

30. Yu Q, Sicinska E, Geng Y, Ahnström M, Zagozdzon A, Kong $\mathrm{Y}, \mathrm{Gardner} \mathrm{H}$, et.al. Requirement for CDK4 kinase function in breast cancer. Cancer Cell. 2006 Jan;9(1):23-32.

31. Liu F, Korc M. Cdk4/6 Inhibition Induces EpithelialMesenchymal Transition and Enhances Invasiveness in Pancreatic Cancer Cells. Mol Cáncer Ther. 2012 11; 2138.10.1158/1535-7163.MCT-12-0562.

32. Goldstein AM, Chidambaram A, Halpern A, Holly EA, Guerry IV D, et.al. Rarity of CDK4 germline mutations in familial melanoma.Melanoma Res. 2002 Feb; 12(1):51-5.

33. Merimsky O, Shoenfeld $Y$, Baharav E, Zigelman R, Fishman P. Reactivity to tyrosinase: expression in cancer (melanoma) and autoimmunity (vitiligo). Hum Antibodies Hybridomas. 1996; 7(4):151-6.

34. Sellapan S, Grijalva R, Zhou X. Yam W, Bar Eli M, Mills GB, Yu D. Lineage Infidelity of MDA-MB-435 Cells. Expression of Melanocyte Proteins in a Breast Cancer Cell Line. Cancer Res May 15, 2004 64; 3479.doi: 10.1158/0008-5472. CAN-3299-2.

35. Berset $M$, Cerottini JP, Guggisberg $D$, Romero $P$, et al. Expression of Melan-A/MART-1 antigen as a prognostic factor in primary cutaneous melanoma. Int J Cáncer 2001;20 (95): 73-7.

36. Tazzari M, Palassini E, Vergani B, Villa A, Rini F, Negri T, et al. Melan-A/MART-1 immunity in a EWS-ATF1 translocated clear cell sarcoma patient treated with sunitinib: a case report. BMC Cancer 2015, 15:58 doi:10.1186/s12885015-1044-0

37. Hoffman $M$, Stoss $O$, Shi $D$, Büttner $R$, Van de Vijver $M, K i m$ W, et al. Assessment of a HER2 scoring system for gastric cancer: results from a validation study. Histopathol 2008; 52 (7) 797-895. DOI: 10.1111/j.13652559.2008.03029.x.

38. Hirsch FR, Franklin WA, Veve R, Varella-García M, Bunn Jr PA.HER2/neu expression in malignant lung tumors. Sem Oncol 2002; 29 (1, S1): 51-58 doi:10.1053/sOnc.2002.31523 
39. Leppilampi M, Koistinen P, Savolainen E-R, Hannuksela J, Parkkila AK, et al. The Expression of Carbonic Anhydrase II in Hematological Malignancies. Clin Cancer Res 2002: 8; 2240-2245.

40. Atkins $M$, Regan $M$, McDermott $D$, Mier J, Stanbrigde E, Youmans A, Febbo P, et al. Carbonic Anhydrase IX EXpression Predicts Outcome of Interleukin 2 Therapy for Renal Cancer. Clin Cancer Res 2005; 11; 3714-3721, doi: 10.1158/1078-0432.CCR-04-2019.

41. Olive PL, Aquino-Parsons C, MacPhail SH, Liao S-Y, Raleigh $\mathrm{JA}$, et al. Carbonic Anhydrase 9 as an Endogenous Marker for Hypoxic Cells in Cervical Cancer. Cancer Res 2001; 61: 8924-8929.

42. Türeci Ö, Sahin U, Vollmar E, Siemer S, Göttert S, Seitz G, Parkkilal A-K, et al. Human carbonic anhydrase XII: cDNA cloning, expression, and chromosomal localization of a carbonic anhydrase gene that is overexpressed in some renal cell cancers. PNAS 1998; 95 (13) 7608-7613.

43. Kim S, Kim N, Dong B, Boren D, Lee SA, Das Gupta J, Gaughan $C$, et al. Integration Site Preference of Xenotropic Murine LeukemiaVirus-Related Virus, a New Human Retrovirus Associated with Prostate Cancer. J. Virol 2008; 82 (20): 9964-9977.

44. Bosch FX, Manos MM, Muñoz N, Sherman M, Jansen AM, Peto J, et al. Prevalence of Human Papillomavirus in Cervical Cancer: a Worldwide Perspective. International Biological Study on Cervical Cancer (IBSCC) Study GroupJ Natl Cancer Inst 1995; 87 (11): 796-802 doi: 10.1093/jncj/87.11.796.

45. Centers for Disease Control and Prevention (CDC).HPVAssociated Penile Cancer Rates by Race and Ethnicity. Human papillomavirus-associated cancers-United States, 2004-2008 MMWR 2012; 61(15):258-261.
46. Chaturvedi AK, Engels EA, Pfeiffer RM, Hernandez BY, Xiao W, et al. Papillomavirus and Rising Oropharyngeal Cancer Incidence in the United States. J Clin Oncol.2011; 29:4294-4301.

47. Fáhraeus R, Lu HL, Emberg I, Finke J, Rowe M, Klein G, et al. Expression of Epstein-Barr virus-encoded proteins in nasopharyngeal carcinoma. Int J Cancer 1998; 42 (3): 329-338 DOI 10.1002/ijc.2910420305.

48. Bollard CM, Gottschalg S, Leen AM, Weiss H, Straathof KC, Carrum G, et al. Complete responses of relapsed lymphoma following genetic modification of tumor-antigen presenting cells and T-lymphocyte transfer. Blood 2007; 110 (8):2838-2845.

49. Khan AA1, Khan Z2, Warnakulasuriya S3.Cáncer associated Toll like receptor modulation and insinuation in infection susceptibility: association or coincidence? Ann Oncol. 2016 Feb 9.pii: mdw053. Epub ahead of print.

50. Mukherjee D, Devi KR, Deka M, Malakar M, et al. Association of toll-like receptor $2 \Delta 22$ and risk for gastric cancer considering main effects and interactions with smoking: a matched case-control study from Mizoram, India. Tumour Biol. 2016 Feb 15. Epub ahead of print.

51. Hirvonen K, Bäck L, Haglund C, et al. Toll-like receptor 5 and 7 expression in adenoid cystic carcinoma of major salivary glands. Tumour Biol. 2016 Feb 18. Epub ahead of print.

52. Jha HC, Banerjee $S$, Robertson E. The Role of gamma herpesviruses in cancer pathogenesis. Pathogens. 2016 Feb 6; 5(1).pii: E18. doi: 10.3390/pathogens5010018.

53. Baggio L, Laureano ÁM, da Rocha Silla LM, Lee DA. Natural killer cell adoptive immunotherapy: Coming of age. Clin Immunol. 2016 Feb 13. pii: S1521-6616(16)30019-5. doi: 10.1016/j.clim.2016.02.003. Epub ahead of print. 